\title{
PEMANFAATAN KOMPONEN TRAFO BEKAS CHARGER HANDPHONE UNTUK LAMPU DARURAT
}

\section{Utilization Of Used Trafo Components Handphone Charger For Emergency Lights}

\author{
${ }^{1)}$ Syahrir Abdussamad, ${ }^{2)}$ Swastiani Dunggio \\ ${ }^{1 *}$ Program Studi Teknik Elektro Fakultas Teknik Universitas Negeri Gorontalo \\ ${ }^{2)}$ Program Studi Ilmu Pemerintahan Fakultas Sospol Universitas Ichsan Gorontalo \\ *Email: syahrirabdussamad@ung.ac.id
}

\begin{abstract}
ABSTRAK
Lampu darurat sebagai penerangan sangat diperlukan oleh manusia untuk mengenali suatu objek secara visual. Oleh karena itu organ tubuh yang mempengaruhi penglihatan seperti mata, syaraf dan pusat syaraf penglihatan di otak. Dalam pembuatan lampu darurat di Desa Tunggulo Kecamatan Tilongkabila Kabupaten Bone Bolango yang menjadi sasaran kegiatan ini adalah rema muda. Dengan memperkenalkan lampu darurat yang mudah dibuat berdasarkan diagram rangkaian yang telah disediakan. Lampu darurat ini sifatnya sementara karena hanya menggunakan sumber baterei 1,5 Vdc yang dapat menyalakan lampu Led 220 Vac dengan waktu menyala sampai kurang lebih 4 jam dan dengan memanfaatkan trafo bekas charger handphone. Tujuan kegiatan ini adalah agar supaya rema muda di Desa Tunggulo Kecamatan Tilongkabila Kabupaten Bonebolango, dapat membuat lampu darurat yang memanfaatkan bekas charger handphone berupa trafo Joule Thief yang nantinya akan dibuat suatu mini inverter untuk menyalakan lampu LED yang tidak memiliki driver LED. Metode yang digunakan adalah pelatihan dan praktek langsung pembuatan lampu darurat dengan sasaran masyarakat adalah rema muda. Metode praktek langsung berupa pendampingan kepada rema muda agar dapat mengunakan alat dan memilih komponen yang akan digunakan. Hasil yang diperoleh, mitra mampu membuat lampu darurat secara mandiri, mitra memiliki pengetahuan tentang komponen yang akan digunakan pada lampu darurat. Setelah pengabdian ini dilakukan, mitra mulai menyadari pentingnya memanfaatkan barang bekas charger handphone sebagai komponen tambahan pembuatan lampu darurat.
\end{abstract}

\section{Kata kunci: Lampu darurat; trafo Joule Thief}

\begin{abstract}
Emergency lights as lighting are needed by humans to recognize an object visually. Therefore the organs of the body that affect vision such as eyes, nerves, and the nerve center of vision in the brain. In making emergency lights in Tunggulo Village, Tilongkabila District, Bone Bolango Regency, the target of this activity were young teenagers. By introducing emergency lights that are easily made based on the circuit diagram that has been provided. This emergency light is temporary because it only uses a $1.5 \mathrm{Vdc}$ battery source that can turn on the 220 Vac Led lights with up to about 4 hours and by utilizing a former handphone charger transformer. The purpose of this activity is so that young people in Tunggulo Village, Tilongkabila District, Bonebolango Regency, can make an emergency lamp that utilizes a former handphone charger in the form of a Joule Thief transformer that will later be made a mini inverter to turn on LED lights that do not have LED drivers. The method used is training and the direct practice of making emergency lights with the target community is young
\end{abstract}


teenagers. The direct practice method is to provide assistance to young teenagers so they can use the tools and choose the components to be used. The results obtained, partners are able to make emergency lights independently, partners have knowledge of the components that will be used in emergency lights. After this dedication was carried out, partners began to realize the importance of utilizing used goods from handphone chargers as an additional component for making emergency lights.

\section{Keywords: Emergency lights; Joule Thief transformer}

\section{PENDAHULUAN}

Kegiatan pengabdian dengan tema Pemanfaatan Trafo Bekas Charger Handphone untuk Lampu Darurat yang dilaksanakan di Desa Tunggulo Kecamatan Tilongkabila Kabupaten Bone Bolango dengan sasaran kelompok masyarakat adalah rema muda, berjalan dengan lancar dimana masyarakat dengan aktif melaksanakan kegiatan pelatihan dan praktek langsung dalam pembuatan lampu darurat. Sebelum melaksanakan pengabdian ini kami melakukan survei langsung dilapangan untuk mengetahui apakah mitra dapat membuat lampu darurat dengan yang rangkaian yang sederhana. Survei kecil inilah yang menjadi dasar pengabdian dengan permasalahan, masyarakat belum memiliki pengetahuan tentang lampu darurat.

Lampu darurat sebagai penerangan sangat diperlukan oleh manusia untuk mengenali suatu objek secara visual. Oleh karena itu organ tubuh yang mempengaruhi penglihatan seperti mata, syaraf dan pusat syaraf penglihatan di otak. Untuk kebutuhan di masyarakat secara umum, lampu penerangan merupakan hal yang diperlukan oleh masyarakat untuk dapat beraktivitas seperti belajar, membaca, memasak, menjahit dan lain sebaginya. Lampu darurat yang diperkenalkan ke masyarakat khususnya di Desa Tunggulo Kecamatan Tilongkabila Kabupaten Bone Bolango adalah bagaimana membuat suatu penerangan yang sifatnya darurat ketika listrik PLN mati, dengan hanya memanfaatkan komponen dari charger handphone yang sudah tidak terpakai/rusak dikombinasikan dengan beberapa komponen elektronika yang mudah di dapat.

Saat ini semakin banyak masyarakat yang menggunakan cahaya lampu terutama di daerah perkotaan yang sibuk dengan berbagai aktivitas terutama yang sangat mebutuhkan cahaya lampu (seperti : membaca, bekerja, menulis, dan lain sebagainya) hal tersebut dapat membuat daya listrik berkurang bahkan terkadang listrik menjadi padam dan aktivitas yang sedang dilakukan menjadi terhambat.

Untuk mengatasi masalah tersebut diperlukan adanya lampu darurat dengan memanfaatkan trafo bekas charger handphone untuk membuat Joule Thief $1,5 \mathrm{~V}_{\mathrm{DC}}$ to $220 \mathrm{~V}_{\mathrm{AC}}$ Light Mini Simple Inveter. (Hermawan R.A, 2017)

Pemanfaatan komponen bekas charger handpone digunakan sebagai alternative pembuatan lampu darurat yang nantinya dapat digunakan oleh masyarakat ketika sumber listrik dari PLN mengalami pemadaman. Hasil penelitian menunjukkan bahwa rancangan inverter mini $1.5 \mathrm{Vdc}$ to 220 Vac dengan Joule Thief dapat menyalakan lampu LED 220 Vac tanpa driver. Pengujian dilakukan pada lampu led 220 Vac tanpa driver dengan kapasitas daya setiap 1 lampu LED adalah 1 watt. Pengujian dilakukan terhadap ketahanan sumber dc berupa baterei daya 1.5 Vac. Dari pengujian untuk lampu LED 1, 2 dan 3 ternyata arus dan tegangan berangsurangsur turun akibat pemakaian lampu LED. Penggunaan sumber baterei cepat habis terhadap waktu terjadi pada pemakaian beban untuk 3 lampu LED. Perancangan alat dapat dimanfaatkan sebagai lampu 
darurat ketika sumber listrik dari PLN dengan lama waktu yang diperlukan untuk menyalakan LED kurang lebih 4 jam. (Abdussamad, 2020), mengenai hal ini lampu darurat sejalan dengan (Rony H. R. Fora, 2010) dan (Yuliana et al., 2017)

Pada pengabdian yang dilakukan sejalan dengan penelitian (Abdussamad, 2020), dimana penulis membuat lampu darurat yang menggunakan komponen charger HP yang sudah tidak terpakai lagi yang digunakan sebagai komponen tambahan dalam pembuatan lampu darurat dan hanya memerlukan sumber tegangan 1,5 $\mathrm{V}_{\mathrm{DC}}$ sebagai sumber untuk menyalakan lampu Led $220 \mathrm{~V}_{\mathrm{AC}}$.

Tujuan kegiatan ini adalah agar supaya rema muda di Desa Tunggulo Kecamatan Tilongkabila Kabupaten Bonebolango, dapat membuat lampu darurat yang memanfaatkan bekas charger handphone berupa trafo Joule Thief yang nantinya akan dibuat suatu mini inverter untuk menyalakan lampu LED yang tidak memiliki driver LED

\section{Permasalahan Mitra}

Sebelum melaksanakan pengabdian, kami melakukan peninjauan lokasi, dengan mendatangi kantor Desa Tunggulo Kecamatan Tilongkabila Kabupaten Bonebolango, dan berdiskusi dengan kepala desa dan aparat desa, tentang pengadian yang akan dilakukan. Adapun tema yang diangkat adalah membuat lampu darurat sebagai pengganti penerangan lampu darurat ketika ada pemadaman listrik. Berdasarkan diskusi ini maka, dapat dipastikan mitra belum mampu membuat lampu darurat yang menggunakan komponen trafo dari cars hp yang sudah tidak terpakai lagi.

Permasalah mitra inilah, kemudian menjadi acuan kami untuk melaksanakan pelatihan dan praktek langsung 1) Bagaimana merancang system lampu darurat/emergensi yang menfaatkan trafo bekas cars HP di kantor Desa Tunggulo
Kecamatan Tilongkabila Kabupaten Bone Bolango; 2) Bagaimana alat yang dibuat dapat digunakan secara maksimal oleh masyarakat khususnya penerangan ketika mati lampu..

\section{SOLUSI DAN TARGET LUARAN}

\section{Solusi Permasalahan}

Solusi yang ditawarkan untuk menyelesaikan permasalahan yang telah dikemukakan adalah bagaimana mitra dapat membuat sebuah lampu darurat memanfaatkan trafo bekas cars HP yang sudah tidak terpakai untuk dijadikan alat bantu penerangan jika lampu dari PLN mati di Desa Dunggala Kecamatan Tapa Kabupaten Bone Bolango, mencakup : 1) Menyiapkan alat dan bahan yang akan digunakan, 2) Membuat rangkaian system lampu darurat, 3) Mencoba hasil rancangan apakah berhasil atau tidak

\section{Luaran dan Target Capaian}

Luaran dan target capaian adalah lampu darurat sebagai penerangan darurat ketika ada pemadaman listrik. Mitra yang melakukan praktek langsung sudah dapat membuat lampu darurat dengan lamanya menyala sekitar 4 jam.

\section{METODE PELAKSANAAN KEGIATAN}

Secara umum kegiatan pengabdian yang dilaksanakan di Desa Tunggulo Kecamatan Tilongkabila Kabupaten Bone Bolango adalah dengan sasaran kelompok masyarakat khususnya rema muda. Metode dalam pengabdian yang diberikan kepada rema muda ini dalam bentuk pelatihan dan praktek, mitra diberikan pengetahuan mengenai alat dan bahan yang akan digunakan kemudian mitra diberikan kesempatan untuk praktek langsung dengan alat dan komponen yang sudah dipersiapkan. Pelatihan dan praktek yang diberikan kepada rema muda adalah 
bagaimana mitra dapat membuat lampu darurat yang memanfaatkan charger handphone yang sudah tidak terpakai atau rusak sebagai alternative yang nantinya dapat digunakan oleh masyarakat ketika sumber listrik dari PLN mengalami pemadaman.

Sasaran pengabdian ini adalah kelompok masyarakat rema muda di Desa Tunggulo, adapun langkah-langkah nyata yang akan dilaksanakan untuk menyelesaikan masalah tersebut diuraikan sebagai berikut:

1. Permasalahan : belum adanya pengetahuan kelompok rema muda di Desa Tunggulo tentang lampu darurat yang dapat dibuat dengan memanfaatkan trafo bekas dari charger handphone yang sudah tidak terpakai.

2. Langkah yang dapat dilakukan untuk mengatasi masalah tersebut yaitu : membuat pelatihan dan praktek langsung dengan menggunakan alat dan komponen yang sudah disediakan sebelumnya. Dalam pelaksanaan pelatihan dan praktek langsung kepada masyarakat memang pada umumnya mengalami kendala seperti penggunaan alat elektronik bagi sebagian mitra merasa kaku akan tetapi dengan pendampingan yang diberikan, mitra sudah mampu menggunakan alat dan komponen sesuai petunjuk yang diberikan. Praktek perakitan sistem lampu darurat untuk mitra menggunakan gambar komponen dengan diagram satu garis yang menghubungkan satu komponen dengan komponen yang lain sehingga mitra dapat melihat dan menghubungkannya menjadi satu sistem yang utuh yakni sistem lampu darurat.

\section{HASIL DAN PEMBAHASAN}

Kegiatan yang dilaksanakan bertempat di Desa Tunggulo Kecamatan Tilongkabila Kabupaten Bone Bolango dengan tema Pemanfaatan Trafo Bekas
Charger Handphone untuk Joule Thief Inverter $1,5 \mathrm{~V}_{\mathrm{DC}}$ to $220 \mathrm{~V}_{\mathrm{AC}}$ berjalan dengan lancar dengan melibatkan rema muda di Desa Tunggulo Kecamatan Tilongkabila Kabupaten Bone Bolango.

Hasil yang diperoleh dari praktek yang dilakukan oleh rema muda di Desa Tunggulo Kecamatan Tilongkabila Kabupaten Bone Bolango adalah adanya rancangan inverter mini yang komponen tambahannya menggunakan trafo Joule Thief yang merupakan komponen dari charger handphone yang sudah rusak. Seperti yang diperlihatkan pada Gambar 1 untuk pelatihan yang diikuti oleh rema muda.

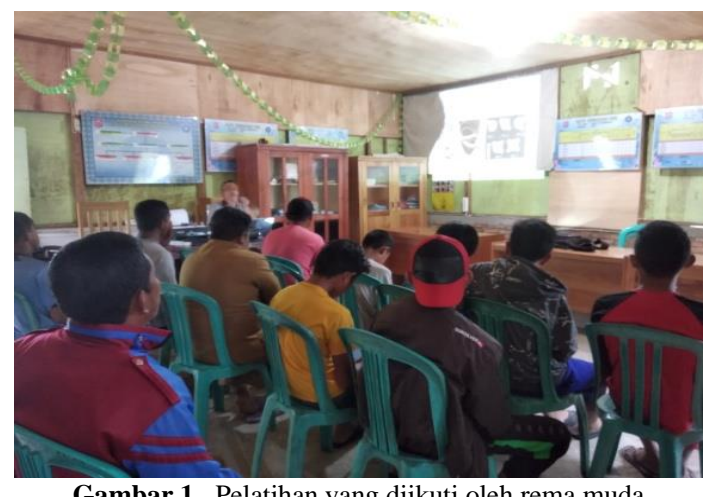

Gambar 1. Pelatihan yang diikuti oleh rema muda

Kegiatan praktek yang dilakukan oleh rema muda diawali dengan membaca diagram gambar rangkaian untuk sistem lampu darurat. Setelah itu memilih komponen yang akan dipakai dalam sistem lampu darurat, kemudian menyiapkan alat dan bahan yang akan digunakan.

Sebelum dilakukan perakitan sistem lampu darurat, kami sebagai pendamping memastikan bahwa yang dipilih sesuai dengan kebutuhan. Setelah pemilihan alat dan bahan sudah sesuai langkah selanjutnya adalah merakit komponen satu demi satu sesuai dengan tata letak dari komponen yang sudah ada di gambar rangkaian sistem lampu darurat. Penyesuaian komponen dengan mengikuti petunjuk gambar, makanya jika mitra tidak jeli melihat gambar akan berakibat pada sistem lampu darurat yang dibuat tidak akan menyala 
atau mati. Praktek pembuatan lampu darurat diperlihatkan pada Gambar 2.
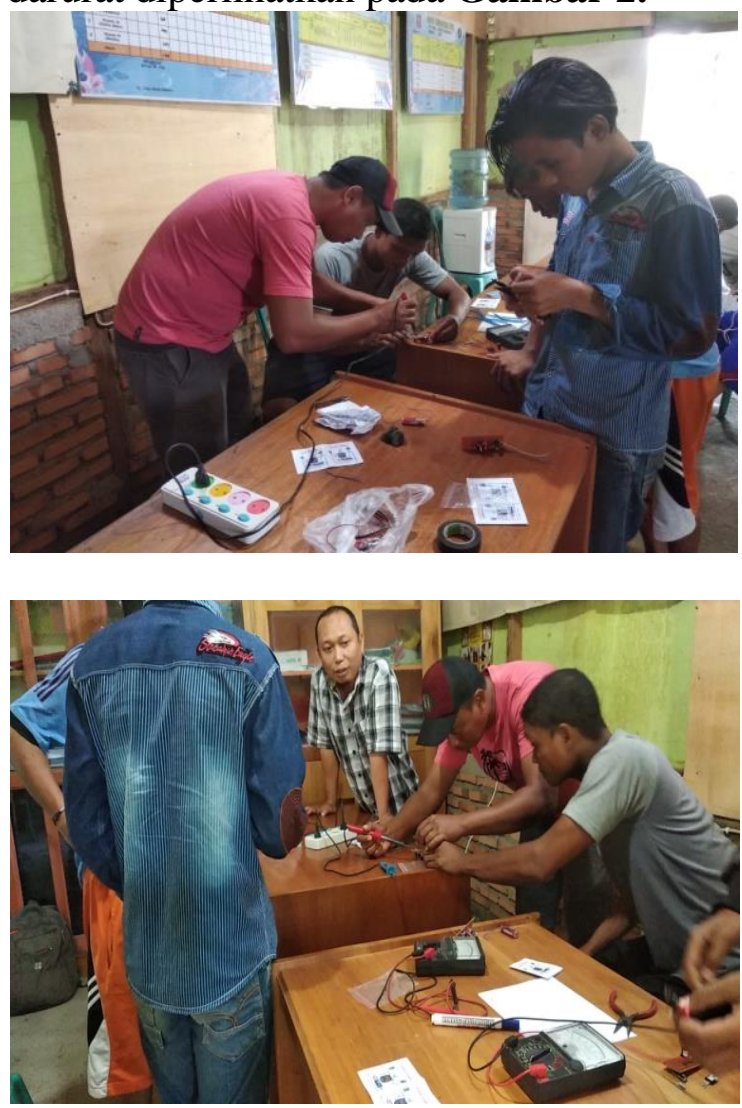

Gambar 2. Praktek pembuatan lampu darurat oleh rema muda

Untuk menganalisa berapa lama waktu yang dibutuhkan oleh baterai untuk memberikan sumber tegangan pada sistem lampu darurat maka perlu dilakukan pengujian terhadap arus searah dan tegangan searah serta berapa lama waktu yang diperlukan oleh baterai untuk menyalakan lampu LED. Pengujian ini menggunakan 3 buah alat yakni 2 multimeter analog dan 1 multimeter digital seperti yang diperlihatkan pada Gambar 3. (Abdussamad, 2020)

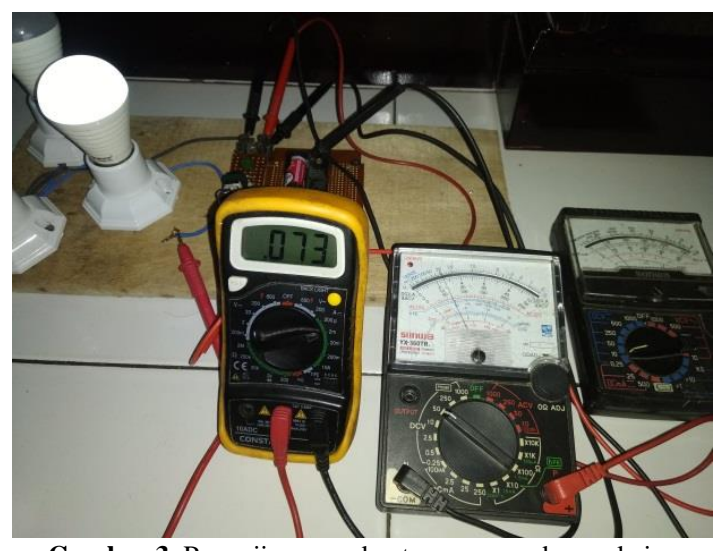

Gambar 3. Pengujian arus dan tegangan pada rangkaian

Data pengujian yang dilakukan untuk mengetahui berapa arus searah dan tegangan searah serta waktu yang dibutuh baterai untuk menghidupkan lampu LED iperlihatkan pada Tabel 1.

Table 1. Pengujian 1 lampu LED tanpa driver dengan daya 1 watt

\begin{tabular}{lllll}
\hline \multirow{2}{*}{ NO } & \multirow{2}{*}{ ARUS $(\mathbf{m A})$} & \multicolumn{2}{c}{ TEGANGAN $\left(\mathbf{V}_{\mathbf{D C}}\right)$} & \multirow{2}{*}{ WAKTU } \\
\cline { 3 - 4 } & & INPUT & OUTPUT & \\
\hline 1 & 0,076 & 1,9 & 16 & $01: 40: 00$ \\
\hline 2 & 0,075 & 1,8 & 15,5 & $01: 50: 00$ \\
\hline 3 & 0,074 & 1,7 & 15 & $02: 05: 00$ \\
\hline 4 & 0,073 & 1,7 & 15 & $02: 10: 00$ \\
\hline 5 & 0,072 & 1,7 & 15 & $02: 20: 00$ \\
\hline 6 & 0,070 & 1,2 & 13 & $02: 50: 00$ \\
\hline 7 & 0,068 & 1,1 & 12,5 & $03: 20: 00$ \\
\hline 8 & 0,067 & 1,1 & 12 & $04: 00: 00$ \\
\hline 9 & 0,065 & 1 & 11 & $04: 25: 00$ \\
\hline 10 & 0,064 & 0,9 & 10 & $04: 55: 00$ \\
\hline 11 & 0,063 & 0,8 & 10 & $05: 10: 00$ \\
\hline
\end{tabular}

Seperti terlihat pada Tabel 1, arus listrik yang mengalir untuk pengujian pertama menunjukkan angka 0,076 $\mathrm{mA}$ seiring dengan penggunaan beban lampu maka waktu yang dibutuhkan juga selalu meningkat. Seiring meningkatnya waktu pengujian maka arus yang terlihat menurun yakni sampai pada $0,063 \mathrm{~mA}$. Hal yang sama terjadi pada tegangan Input tegangannya $1,9 \mathrm{Vdc}$ dan tegangan output 16 Vdc. Setelah pengujian dilakukan tegangan input dan tegangan output menurun sampai pada tegangan input 0,8 $\mathrm{Vdc}$ dan tegangan output $10 \mathrm{Vdc}$.

Keadaan lampu untuk pengujian pertama terlihat terang yang pada akhirnya akan mati sampai pada arus 0,063 mA, tegangan input $0,8 \mathrm{Vdc}$ dan tegangan input 10 Vdc. Hasil pengujian dan analisis ini sejalan dengan penelitian (Abdussamad, 
2020), yang mengunakan beban lampu LED $220 \mathrm{~V}_{\mathrm{AC}}$ dengan daya 1 watt. Dalam penelitiannya, dengan menggunakan sumber batu baterei $1,5 \quad \mathrm{~V}_{\mathrm{DC}}$ dapat memberikan sumber tegangan arus searah pada mini inverter yang salah satu komponen utama adalah trafo Joule Thief.

Jika dibandingkan dengan penelitian sebelumnya (Rony H. R. Fora, 2010) \& (Yuliana et al., 2017), dari sisi rancangan lampu darurat yang digunakan sangat sederhana rangkaiannya dan komponennya mudah didapat. Maka mitra dapat membuat rancangan sistem darurat yang dapat bertahan \pm 4 jam waktu nyalanya.

Pembahasannya dapat dijabarkan dengan mengacu pada sumber yang relevan adalah dengan mengacu pada jurnal (Abdussamad, 2020). Lampu darurat yang dibuat oleh rema muda di Desa Tunggulo Kecamatan Tilongkabila Kabupaten Bone Bolango dalam bentuk praktek langsung, menggunakan sumber batu baterai tipe AA 1,5 $\mathrm{V}_{\mathrm{DC}}$. Dengan tegangan sumber 1,5 $\mathrm{V}_{\mathrm{DC}}$ dapat mengaktifkan mini inverter yang fungsinya dapat menyalakan lampu LED $220 \mathrm{~V}_{\mathrm{AC}}$. Penggunaan arus untuk pengujian pertama adalah $0,076 \mathrm{~mA}$ dengan tegangan input 1,9 VDC dari sisi sumber batu bateai dan output tegangan 16 VDC dengan pengambilan awal waktu jam 01:40:00. Dari pengujian awal ini dapat dianalisa bahwa penggunaan sumber tegangan baterai yang masih baru adalah $1,9 \mathrm{~V}_{\mathrm{DC}}$ dapat menghasilkan sumber tegangan keluaran mini inverter $16 \mathrm{~V}_{\mathrm{DC}}$ yang dapat menyalakan lampu LED 1 watt. Seperti yang terlihat pada data pengujian Tabel 1, ketika lampu darurat dinyalakan ada pengurangan tegangan dari sumber batu baterai 0,1 VDC dengan penambahan waktu nyala 10 menit pada pengujian kedua. Setelah mengalami beberapa pengujian, dan terlihat pada pengujian ke 11 dengan sumber arus 0,063 mA, tegangan sumber batarai menjadi $1,1 \mathrm{~V}_{\mathrm{DC}} \quad\left(1,9 \mathrm{~V}_{\mathrm{DC}}\right.$ $\left.0,8 \mathrm{~V}_{\mathrm{DC}}=1,1 \mathrm{~V}_{\mathrm{DC}}\right)$ yang masih dapat menyalakan lampu LED akan tetapi nyala lampu LED semakin redup dengan waktu nyala \pm 4 jam.

Dengan mengacu pada hasil analisis ini, maka mitra yang melaksanakan praktek kiranya dapat mengembangkan potensi lampu darurat ini sebagai sumber informasi maupun sumber penghasilan untuk masyarakat itu sendiri.

\section{KESIMPULAN DAN SARAN}

Kegiatan Pengabdian yang dilaksanakan di Desa Tunggulo Kecamatan Tilongkabila Kabupaten Bone Bolango menyimpulkan sebagai berikut: Dengan diberikannya pelatihan dan praktek tentang pembuatan lampu darurat yang memanfaatkan trafo bekas charger handphone untuk lampu darurat, mitra menjadi paham menggunakan alat dan memilih komponen pendukung lampu darurat sehingga mitra dapat membuatnya sendiri dengan menggunakan diagram rangkaian; Pengujian yang dilakukan menggambarkan bahwa penggunaan sumber tegangan batu baterai semakin berkurang ditandai dengan tegangan Input dari $1,9 \mathrm{~V}_{\mathrm{DC}}$ menjadi 0,8 $\mathrm{V}_{\mathrm{DC}}$ dan Output dari $16 \mathrm{~V}_{\mathrm{DC}}$ menjadi 10 $\mathrm{V}_{\mathrm{DC}}$ sedangkan dilihat dari sisi waktu yang diperlukan untuk menyalakan lampu LED \pm 4 jam.

\section{DAFTAR PUSTAKA}

Abdussamad, S. (2020). Rancang Bangun Inverter Mini $1.5 \mathrm{Vdc}$ to $220 \mathrm{Vac}$ Untuk Lampu Darurat. Jurnal Teknik, 18(1), 7-16. https://doi.org/10.37031/jt.v18i1.65

Hermawan R.A. (2017). Joule Thief $1.5 \mathrm{v}$ mini inverter dengan trafo bekas charger. Retrieved from https://espelima.blogspot.com/2017/05 /joule-thief-15v-mini-inverter-dgntrafo-bekas-charger-hp.html

Rony H. R. Fora. (2010). Perancangan dan Pembuatan Lampu Darurat Untuk Daerah Rawan Bencana Alam. Jurnal Teknik WAKTU, 08(02), 24-30. Retrieved from 
file:///C:/Users/ais/Downloads/807517972-1-SM (1).pdf

Yuliana, R., Muksin, U., Fisika, J., Fisika, P. S., Fisika, J., July, R., \& July, A. (2017). Perancangan Perangkat Lampu Emergency Multifungsi. Journal of Aceh Physics Society (JAcPS), 6(2), 30-33. 